\title{
DESIGN OF A PARTICIPATORY DECISION MAKING AGENT ARCHITECTURE BASED ON ARGUMENTATION AND INFLUENCE FUNCTION - APPLICATION TO A SERIOUS GAME ABOUT BIODIVERSITY CONSERVATION
}

\author{
Alessandro Sordoni ${ }^{1}$, Jean-Pierre Briot ${ }^{1,2}$, \\ IsABelle Alvarez ${ }^{3}$, Eurico VASCONCElos ${ }^{2}$, \\ Marta de Azevedo Irving ${ }^{4}$ and Gustavo Melo ${ }^{4}$ \\ Communicated by J.P. Briot
}

\begin{abstract}
This paper addresses an ongoing experience in the design of an artificial agent taking decisions and combining them with the decisions taken by human agents. The context is a serious game research project, aimed at computer-based support for participatory management of protected areas (and more specifically national parks) in order to promote biodiversity conservation and social inclusion. Its objective is to help various stakeholders (e.g., environmentalist, tourism operator) to collectively understand conflict dynamics and explore negotiation strategies for the management of parks. In this paper, after introducing the design of our serious game, named SimParc, we will describe the architecture of the decision making agent playing the role of the park manager. In the game, the park manager makes final decisions based on its own analysis and also on the votes of the stakeholders. It includes two modules: 1) individual decision - based on a model of argumentation, which also provides a basis to justify and explain the decision; 2) participatory decision - to take into account the preferences/votes from the stakeholders.
\end{abstract}

\footnotetext{
Received February 10, 2010. Accepted November 10, 2010.

1 Laboratoire d'Informatique de Paris 6 (LIP6), Université Pierre et Marie Curie - CNRS,

Paris, France. alessandro.sordoni@gmail.com; Jean-Pierre.Briot@lip6.fr

2 Computer Science Department, Pontifícia Universidade Católica (PUC-Rio), Rio de Janeiro, RJ, Brazil. jose_eurico@yahoo.com

3 Laboratoire d'Ingénierie pour les Systèmes Complexes (LISC), CEMAGREF, Aubière, France. isabelle.alvarez@cemagref.fr

4 EICOS Program, Universidade Federal do Rio de Janeiro (UFRJ), Rio de Janeiro, RJ,

Brazil. mirving@mandic.com.br; melo.gustavo@yahoo.com
} 
Keywords. Artificial agent, architecture, decision, collective, participatory, argumentation, negotiation, serious game, management of the environment.

Résumé. Cet article présente notre expérience de conception d'un agent artificiel prenant des décisions et capable de prendre également en compte les décisions d'agents humains. Le contexte est un projet de recherche de type jeu sérieux, pour la gestion participative d'espaces protégés (et plus particulièrement de parcs nationaux), de manière à promouvoir conservation de la biodiversité et inclusion sociale. Son objectif est d'aider les différents acteurs sociaux («stakeholders », ex : environnementaliste, opérateur de tourisme) à comprendre la dynamique collective des conflits et d'explorer des stratégies de négociation pour la gestion de parcs. Dans cet article, après avoir introduit la conception du jeu sérieux, nommé SimParc (pour « simulation de gestion participative de parcs »), nous décrivons l'architecture de l'agent décideur jouant le rôle d'un gestionnaire de parc. Dans le jeu, le gestionnaire du parc prend la décision finale en fonction de sa propre analyse de la situation ainsi que des propositions des acteurs sociaux. Il inclut deux modules : (1) décision individuelle - basé sur un modèle d'argumentation, ce qui offre également un point de départ pour justifier et expliquer la décision; (2) décision participative - pour prendre en compte les préférences/votes des acteurs sociaux.

Mots Clés. Agent artificiel, architecture, décision collective, participatif, argumentation, négotiation, jeu sérieux, gestion de l'environnement.

Mathematics Subject Classification. 68N01, 68T35, 91B06, 91B14, 91A90.

\section{INTRODUCTION}

The context of this work is an ongoing research project concerned with exploring computer support for participatory management of protected areas (for biodiversity conservation and social inclusion). Therefore, we designed a serious game, as our objective is educational and epistemic. In this game, humans play some roles (representing stakeholders, e.g., environmentalist, tourism operator...) and discuss, negotiate and take decisions about environment management decisions. The park manager acts as an arbitrator in the game, making a final decision about the types of conservation for each landscape unit and he also explains its decision to all players. Using an artificial manager in place of a human manager allows reproductible experiments with controllable levels of participation and of manager profile (see Sect. 4.1). Its objective is to make decision based on its own analysis of the situation and on the proposals by the players. The agent is also able to explain its decision based on its chain of argumentation. 


\section{The SimParc Project}

\subsection{Project motivation}

A significant challenge involved in biodiversity management is the management of protected areas (e.g., national parks), which usually undergo various pressures on resources, use and access, which results in many conflicts. This makes the issue of conflict resolution a key issue for the participatory management of protected areas. Methodologies intending to facilitate this process are being addressed via bottom-up approaches that emphasize the role of local actors. Examples of social actors involved in these conflicts are: park managers, local communities at the border area, tourism operators, public agencies and NGOs. Examples of inherent conflicts connected with biodiversity protection in the area are: irregular occupation, inadequate tourism exploration, water pollution, environmental degradation and illegal use of natural resources.

Our SimParc project aim is to help various stakeholders at collectively understand conflicts in parks management and negotiate strategies for handling them. The origin of the name SimParc stands in French for "Simulation Participative de Parcs". It is based on the observation of several case studies in Brazil. However, we chose not to reproduce exactly a real case, in order to leave the door open for broader game possibilities.

\subsection{Approach}

Our initial inspiration is the companion modeling (ComMod) approach about participatory methods to support negotiation and decision-making for participatory management of renewable resources [4]. They pioneer method, called MAS/ $\mathrm{RPG}$, consists in coupling multi-agent simulation (MAS) of the environment resources and role-playing games (RPG) by the stakeholders [4]. The RPG acts like a "social laboratory", because players of the game can try many possibilities, without real consequences. Recent offsprings from ComMod, like [8], and [1], proposed further integration of role-playing into simulation, distributed support for role-playing and the insertion of artificial agents, as players or as assistants.

\section{The SimParc Role-Playing Game}

\subsection{Game objectives}

Current SimParc game has an epistemic objective: to help each participant discover and understand the various factors, conflicts and the importance of dialogue for a more effective management of parks. Note that this game is not (or at least not yet) aimed at decision support (i.e., we do not expect the resulting decisions to be directly applied to a specific park). 
The game is based on a negotiation process that takes place within the park council. This council, of a consultative nature, includes representatives of various stakeholders (e.g., community, tourism operator, environmentalist, non governmental association, water public agency...). The actual game focuses on a discussion within the council about the "zoning" of the park, i.e. the decision about a desired level of conservation (and therefore, use) for every sub-area (also named "landscape unit") of the park. We consider nine pre-defined potential levels (that we will consider as types) of conservation/use, from more restricted to more flexible use of natural resources, as defined by the (Brazilian) law. Examples are: Intangible, the most conservative use, Primitive and Recuperation.

The game considers a certain number of players' roles, each one representing a certain stakeholder. Depending on its profile and the elements of concerns in each of the landscape units (e.g., tourism spot, people, endangered species), each player will try to influence the decision about the type of conservation for each landscape unit. It is clear that conflicts of interest will quickly emerge, leading to various strategies of negotiation (e.g., coalition formation, trading mutual support for respective objectives, etc.).

A special role in the game is the park manager. He is a participant of the game, but as an arbiter and decision maker, and not as a direct player. He observes the negotiation taking place among players and takes the final decision about the types of conservation for each landscape unit. (It is important to note that this follows the situation of a real national park in Brazil, where the park management council - composed of representatives of diverse stakeholders - is only of a consultative nature, thus leaving the final decisions to the manager.) Decision by the park manager is based on the legal framework, on the negotiation process among the players, and on his personal profile (e.g., more conservationist or more open to social concerns). He may also have to explain his decision, if the players so demand. We plan that the players and the park manager may be played by humans or by artificial agents.

\subsection{GAME CYCLE}

The game is structured along six steps, as illustrated in Figure 1. At the beginning (step 1), each participant is associated with a role. Then, an initial scenario is presented to each player, including the setting of the landscape units, the possible types of use and the general objective associated to his role. Then (step 2), each player decides a first proposal of types of use for each landscape unit, based on his/her understanding of the objective of his/her role and on the initial setting. Once all players have done so, each player's proposal is made public.

In step 3, players start to interact and to negotiate on their proposals. This step is, in our opinion, the most important one, where players collectively build their knowledge by means of an argumentation process. In step 4, they revise their proposals and commit themselves to a final proposal for each landscape unit. In step 5, the park manager makes the final decision, considering the negotiation process, the final proposals and also his personal profile (e.g., more conservationist 


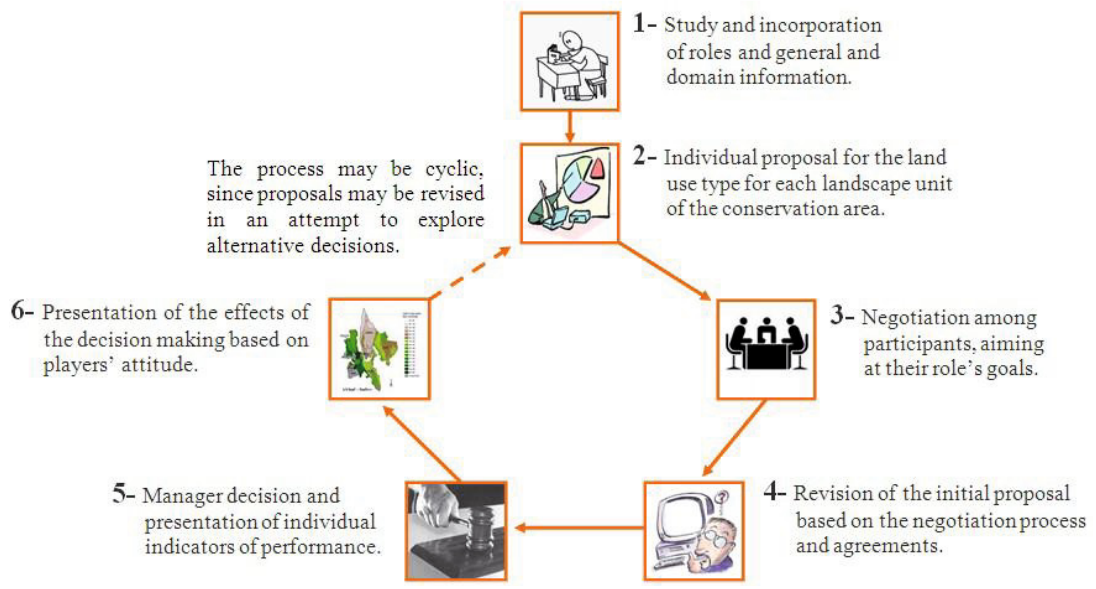

Figure 1. The six steps of the SimParc game.

or more sensitive to social issues). Each player can then consult various indicators of his/her performance (e.g., closeness to his initial objective, degree of consensus, etc.). He can also ask for an explanation about the park manager decision rationales.

The last step (step 6) "closes" the epistemic cycle by considering the possible effects of the decision. In the current game, the players provide a simple feedback on the decision by indicating their level of acceptance of the decision.

A new negotiation cycle may then start, thus creating a kind of learning cycle. The main objectives are indeed for participants: to understand the various factors and perspectives involved and how they are interrelated; to negotiate; to try to reach a group consensus; and to understand cause-effect relations based on the decisions.

An ongoing sub-project plan is to introduce some assistance to players and to the park manager about evaluation of the quality of a decision, using viability theory $[3,13]$. Note that a completely validated model is not indispensable as the park is fictive and the objective is credibility, not realism.

\section{The SimParc game support architecture}

\subsection{Design AND IMPlementation of the ARChitecture}

Our current prototype benefited from our previous experiences (game sessions and prototype) and has been based on a detailed design process. Based on the system requirements, we adopted Web-based technologies (more precisely J2E and JSF) that support the distributed and interactive character of the game as well as an easy deployment. 


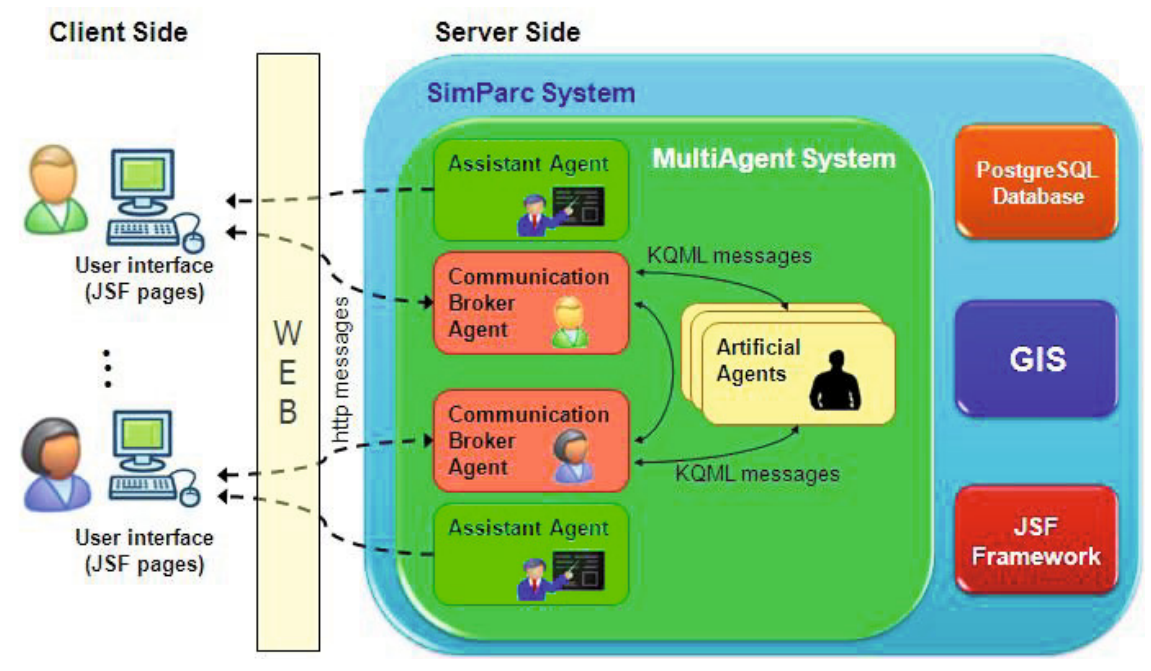

FiguRE 2. SimParc general architecture.

Figure 2 shows the general architecture and communication structure of SimParc current prototype. Distributed users (the players and the park manager) interact with the system mediated internally by communication broker agents (CBA). The function of a CBA is to abstract the fact that each role may be played by a human or by an artificial agent. A CBA also translates user messages in http format into multi-agent KQML format and vice versa. For each human player, there is also an assistant agent offering assistance during the game session (see more details in [13]). During the negotiation phase, players (human or artificial) negotiate among themselves to try to reach an agreement about the type of use for each landscape unit (sub-area) of the park.

A Geographical Information System (GIS) offers to users different layers of information (such as flora, fauna and land characteristics) about the park geographical area. All the information exchanged during negotiation phase, namely users' logs, game configurations, game results and general management information are recorded and read from a PostgreSql database.

\subsection{INTERFACE}

The interface for negotiation is shown at Figure 3. It includes advanced support for negotiation (rhetorical markers and dialogue filtering/structuring mechanisms, see details in [12]), access to different kinds of information about other players, land, law and the help of a personal assistant. The interface for players decision about the types of use at Figure 4 . In this interface, the players can analyze the area based in its different layers (e.g., land, hydrography, vegetation...). 


Proposta Inicial Mapa
Ordem Cronológica Ordem Hierárquica
$\begin{gathered}\text { ( } 16: 57: 45: \text { teste Propôe Eu proponho o uso intensivo para a Unidade } \\ \text { ? } 16: 58: 40: \text { teste2 Discorda Eu discordo e acho que se deve utilisar } \\ \text { ? 16:59:11: teste Pergunta Por quê?; }\end{gathered}$

\section{Filtros e Atributos para a Visualizaçầo da Negociação}

\begin{tabular}{|c|c|c|c|c|c|c|}
\hline \multicolumn{3}{|l|}{ Intenção: } & \multicolumn{2}{|c|}{ Assunto: } & \multicolumn{2}{|l|}{ Emissor: } \\
\hline \multicolumn{2}{|l|}{ Pergunta } & $\hat{\imath}$ & \multicolumn{2}{|c|}{ Unidade de Paisag $\_\hat{\imath}$} & \multicolumn{2}{|l|}{ teste } \\
\hline \multirow{2}{*}{$\begin{array}{l}\text { Emissor: } \\
\text { teste }\end{array}$} & \multicolumn{3}{|l|}{ Intenção: } & \multicolumn{3}{|l|}{ Sobre: } \\
\hline & Propōe & & $\hat{\imath}$ & \multicolumn{2}{|c|}{ Unidade de Paisagem 1} & $\hat{\imath}$ \\
\hline
\end{tabular}

FigurE 3. Current prototype's negotiation GUI.

\subsection{Preliminary evaluation}

The current computer prototype has been tested through two game sessions by domain expert players in January 2009. The 9 roles of the game and the park manager were played by humans. Among these 10 human players, 8 were experts in park management (researchers and professionals, one being a professional park manager in Brazil). The two remaining players were not knowledgeable in park management. One was experienced in games (serious games and video games) and the other one a complete beginner in all aspects. 


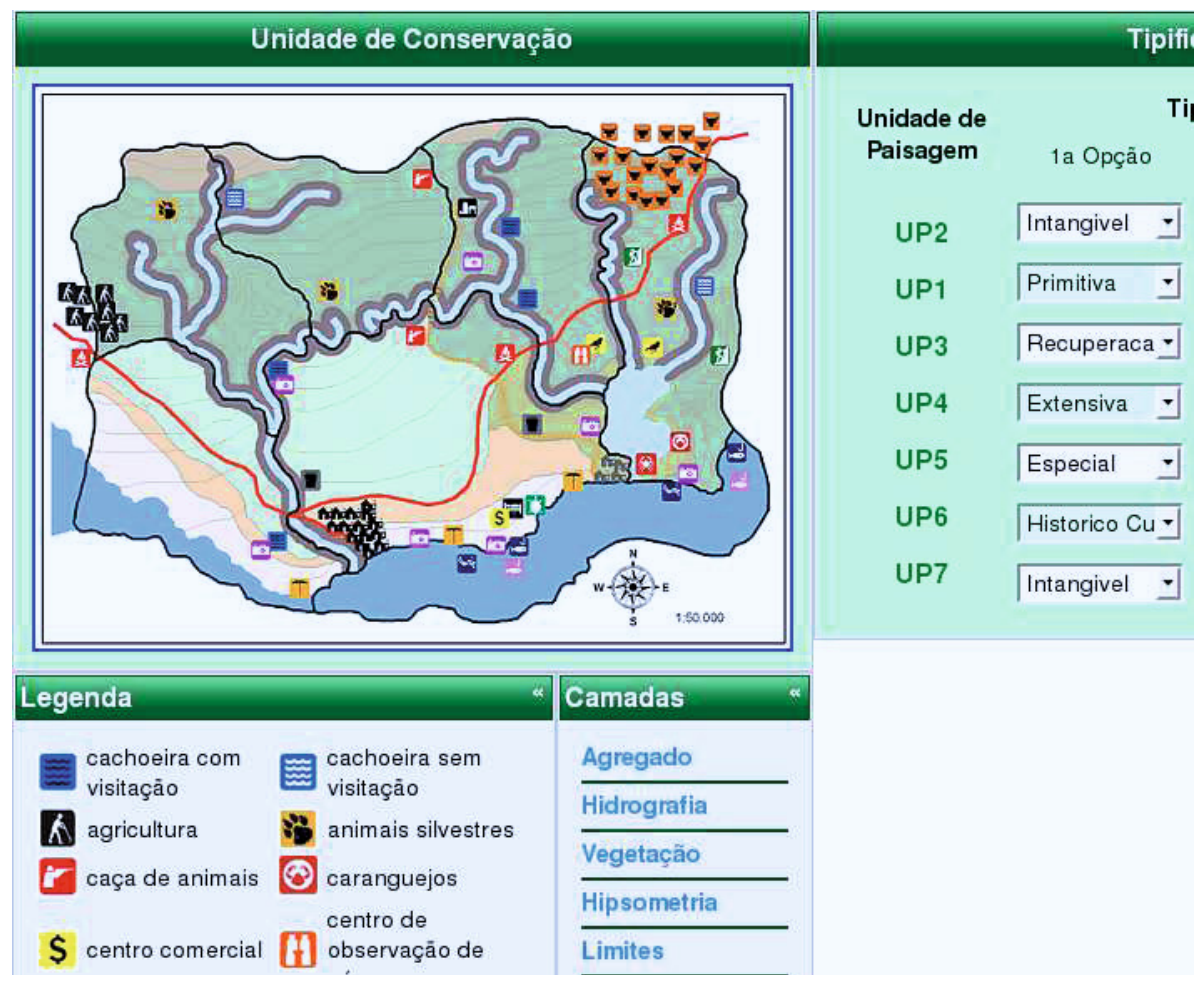

Figure 4. Current prototype's decision GUI.

Overall, the game was well evaluated by the human players. We analyzed data on the game sessions (written questionnaires, recorded debriefing, etc.) and a detailed analysis is presented in [13]. An interesting finding after the sessions was also that all players learned and took benefit of the game. The experts explored and refined strategies for negotiation and management, whereas the beginner player took benefit of the game as a more general educational experience about environmental management. In other words, the game appeared to be tolerant to the actual level of expertise of players, an aspect which had not been planned ahead. We believe these preliminary results are very encouraging and we will soon conduct new game sessions with experts.

\section{THE PARK MANAGER ARTIFICIAL AGENT}

The park manager acts as an arbitrator in the game, making a final decision for types of conservation for each landscape unit and explaining its decision to all players. He may be played by a human or by an artificial agent. Main motivations for an artificial agent are: (1) the possible absence of an expert human player 
during a game session; (2) reproductible experiments with possibility to control the park manager profile as well as his participation level.

We have implemented a prototype implementation of an artificial park manager, based on 2 steps: (1) internal/individual decision by the park manager, based on some argumentation model; (2) merging of the decision by the manager with the votes by the players, based on decision theory (social choice). Traces of argumentation may be used for explaining the rationale of the decision. These two steps/mechanisms could be viewed as modules of decision subprocesses. We believe that complex decision making is achievable by the sequential organization of these modules. Before proceeding to the description of our agent architecture, we present some more detailed motivation for it.

\subsection{OBJeCtives}

Participatory management aims to emphasize the role of local actors in managing protected areas. However, park manager is the ultimate arbiter of all policy on devolved matters. He acts like an expert who decides on validity of collective concerted management policies. Moreover, he is not a completely fair and objective arbiter: he still brings his personal opinions and preferences in the debate. Therefore, we aim to develop an artificial agent modeling the following behaviors.

\subsubsection{Personal preferential profile}

The park manager decision-making process is supposed to be influenced by its sensibility to natural park stakes and conflicts. In decision theory terms, we can affirm that the park manager's preferential profile could be intended as a preference relation over conservation policies. One of the key issues is to understand that we cannot define a strict bijection between preferential profile and preference relation. The agent's preference relation is partially dependent on natural park resources and realities. Moreover, this relation is not likely to be an order or a preorder. Hence, our agent must be able to define dynamically its preference relation according with its preferential profile. We distinguish two preferential profiles:

- Preservationist, who aims to preserve ecosystems and the natural environment.

- Socio-conservationist, who generally accepts the notion of sustainable yield - that man can harvest some forest or animal products from a natural environment on a regular basis without compromising the long-health of the ecosystem.

\subsubsection{Taking into account stakeholders' decisions}

A participatory decision-making leader seeks to involve stakeholders in the process, rather than taking autocratic decisions. However, the question of how much influence stakeholders are given may vary on the manager's preferences and beliefs. Hence, our objective is to model the whole spectrum of participation, from autocratic decisions to fully democratic ones. To do so, we want the park manager 


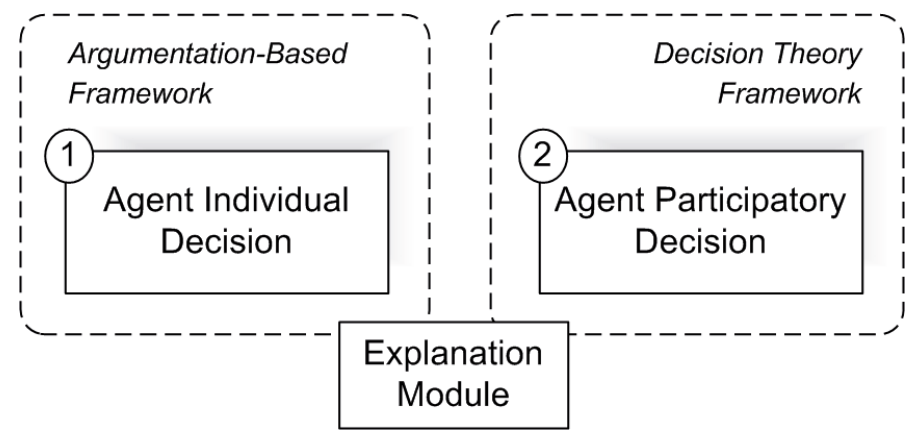

Figure 5. Park Manager Agent 2-Steps decision process.

agent to generate a preference preorder over conservation policies. This is because it should be able to calculate the distance between any two conservation policies. This way, we can merge stakeholders' preference preorders with the manager's one to establish one participatory final decision. Autocratic/democratic manager attitude will be modeled by an additional parameter during the merge process.

\subsubsection{Expert decision}

The park manager's final decision must consider legal constraints related to environmental management; otherwise, non-viable decisions would be presented to the players, thus invalidating the game's learning objectives. These constraints are directly injected in the cognitive process of the agent. Hence, the agent will determine a dynamic preference preorder, according to its preferential profile, over allowed conservation levels.

\subsubsection{Explaining final decision}

In order to favor the learning cycle, the park manager agent must be able to explain its final decision to the players. We can consider that the players could eventually argue about its decision; the agent should then defend its purposes using some kind of argumentative reasoning. Even if such cases will be explored in future work, it is our concern to conceive a cognitive architecture which provides a good basis for managing these situations.

\subsection{Architecture OVERView}

Let us now present an architecture overview of the park manager agent. As depicted in Figure 5, the agent's architecture is structured in two phases. We believe that sequential decision-making mechanisms can model complex cognitive behaviors along with enhanced explanation capabilities.

The first decision step concerns the agent's individual decision-making process: the agent deliberates about the types of conservation for each landscape unit. 
Broadly speaking, the park manager agent builds its preference preorder over allowed levels of conservation. An argumentation-based framework is implemented to support the decision making. The next step of our approach consists in taking into account the players' preferences. The result of the execution is the modified park manager decision, called agent participatory decision, according to the preferences of the stakeholders.

\subsection{Agent individual Decision}

Recently, argumentation has been gaining increasing attention in the multiagent community. Autonomous and social agents need to deliberate under complex preference policies, related to the environment in which they evolve. Generally, social interactions bring new information to the agents. Hence, preference policies need to be dynamic in order to take into account newly acquired knowledge. Dung's work [7] proposes formal proof that argumentation systems can handle epistemic reasoning under open-world assumptions, usually modeled by nonmonotonic logics. Argumentation thus becomes an established approach for reasoning with inconsistent knowledge, based on the construction and the interaction between arguments. Recently, some research has considered argumentation systems capabilities to model practical reasoning, aimed at reasoning about what to do $[2,9,10]$. It is worth noticing that argumentation can be used to select arguments that support available desires and intentions. Consistent knowledge can generate conflicting desires. An agent should evaluate pros and cons before pursuing any desire. Indeed, argumentative deliberation provides a mean for choosing or discarding a desire as an intention.

We could argue that open-world assumptions do not hold in our context. The agent's knowledge base is not updated during execution, since it is not directly exposed to social interactions. Knowledge base and inference rules consistencychecking methods are, therefore, not necessary. However, one key aspect here is to conceive an agent capable of explaining its policy making choices; our concern is to create favorable conditions for an effective and, thus closed, learning cycle. We believe that argumentation "tracking" represents an effective choice for accurate explanations. Conflicts between arguments are reported, following agent's reasoning cycle, thus enhancing user comprehension.

From this starting position, we have developed an artificial agent on the basis of Rahwan and Amgoud's work [10]. The key idea is to use an argumentation system to select the desires the agent is going to pursue: natural park stakes and dynamics are considered in order to define objectives for which to aim. Hence, decisionmaking process applies to actions, i.e. conservation levels, which best satisfy selected objectives. In order to deal with arguments and knowledge representation, we use first-order logic. Various inference rules were formulated with the objective of providing various types of reasoning capability. For example, a simple inference rule for generating desires from beliefs, i.e. natural park stakes, is:

$$
\text { Fire } \rightarrow \text { Avoid_Fires, } 4
$$




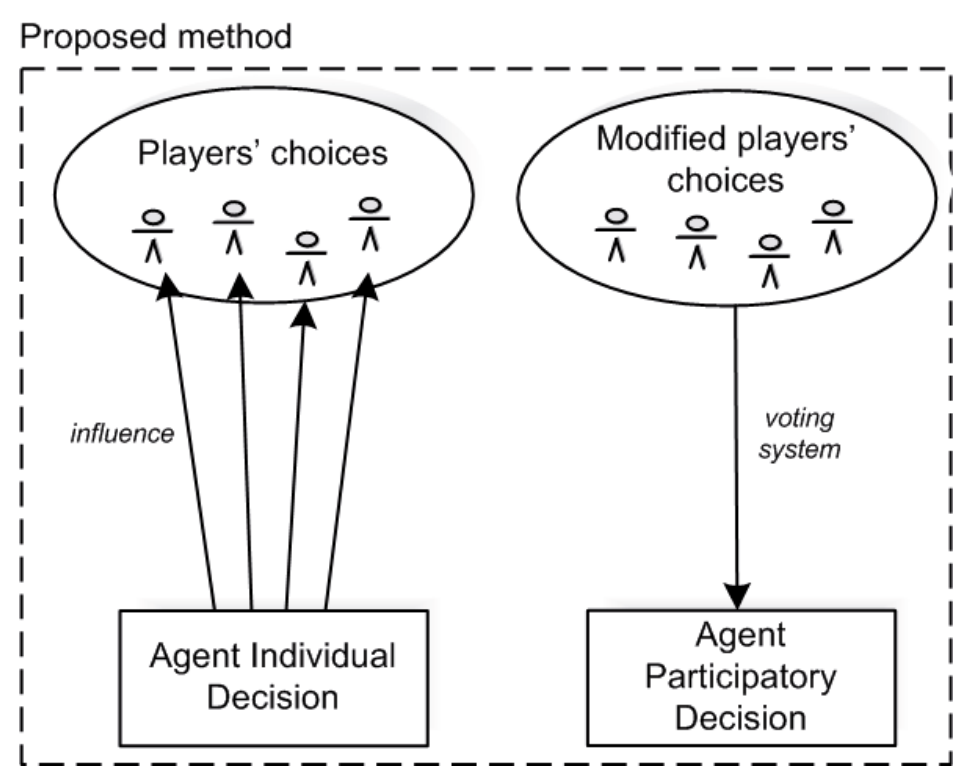

Figure 6. Park manager agent participatory decision.

where Fire (fire danger in the park) is a belief in the agent's knowledge base and Avoid_Fires is the desire that is generated from the belief. The value 4 represents the intensity of the generated desire.

Examples of rules for selecting actions, i.e. level of conservation, from desires are:

$$
\begin{gathered}
\text { Primitive } \rightarrow \text { Avoid_Fires, } 0.4 \\
\text { Intangible } \rightarrow \text { Avoid_Fires, } 0.8
\end{gathered}
$$

where Primitive, Intangible represent the levels of conservation and 0.4, 0.8 represent their utilities in order to satisfy the desire Avoid_Fires.

\subsection{Agent participatory DeCision}

Despite participatory ideals, a whole spectrum of park managers, from autocratic to fully democratic ones, can be measured, depending on how more participatory and democratic decision-making is operationalized. We propose a method, fitted into the social-choice framework, in which participatory attitude is a model parameter.

In a real case scenario, a decision-maker would examine each stakeholder's preferences in order to reach the compromise that best reflects its participatory attitude. Our idea is to represent this behavior by weighting each player's vote according to the manager's point of view.

This concept is illustrated in Figure 6. The process is structured in two phases. Firstly, the manager agent injects its own preferences into players' choices by means 
of an influence function describing the agent's participatory attitude. Stronger influence translates into more autocratic managers. Secondly, the modified players' choices are synthesized, using an aggregation function, i.e. Condorcet voting method. The result of the execution will be the agent participatory decision.

\subsubsection{Example}

Let the following be players' choices, where $\succ$ is a preference relation $(\mathrm{a} \succ \mathrm{b}$ means "a is preferred to b"):

$$
\begin{aligned}
& \text { player }_{1}=\text { Intangible } \succ \text { Primitive } \succ \text { Extensive, } \mathbf{v}_{1}=(3,2,1) \\
& \text { player }_{2}=\text { Extensive } \succ \text { Primitive } \succ \text { Intangible, } \mathbf{v}_{2}=(1,2,3) \\
& \text { player }_{3}=\text { Primitive } \succ \text { Extensive } \succ \text { Intangible, } \mathbf{v}_{3}=(1,3,2) .
\end{aligned}
$$

Let the manager individual decision be:

$$
\text { manager }_{\text {ind }}=\text { Extensive } \succ \text { Primitive } \succ \text { Intangible, } \mathbf{v}_{M}=(1,2,3) .
$$

The players' choices are converted into numeric vectors specifying the candidates' rank for each vote. Let the following be the influence function:

$$
\odot(x, y)= \begin{cases}x & \text { if } x=y \\ x * 1 /|x-y| & \text { otherwise. }\end{cases}
$$

Modified players' vectors will be:

$$
\begin{aligned}
\mathbf{m v}_{1} & =\left\langle\odot\left(\mathbf{v}_{1}(1), \mathbf{v}_{M}(1)\right), \odot\left(\mathbf{v}_{1}(2), \mathbf{v}_{M}(2)\right), \odot\left(\mathbf{v}_{1}(3), \mathbf{v}_{M}(3)\right)\right\rangle \\
& =(1.5,2,0.5) \\
\mathbf{m v}_{2} & =(1,2,3) \\
\mathbf{m v}_{3} & =(1,3,2)
\end{aligned}
$$

In order to find the manager participatory decision, we apply the Choquet integral $\mathcal{C}_{\mu}$ [6] choosing a symmetric capacity measure $\mu(S)=|S|^{2} /|\mathcal{A}|^{2}$, where $\mathcal{A}$ is the candidates set. (Note that this aggregation method is convex, here motivated because the park manager does not favor particular players.)

$$
\mathcal{C}_{\mu}(\text { Intangible })=1.05, \mathcal{C}_{\mu}(\text { Primitive })=2.12, \mathcal{C}_{\mu}(\text { Extensive })=1.27 .
$$

The result of the execution will then be:

$$
\text { manager }_{\text {part }}=\text { Primitive } \succ \text { Extensive } \succ \text { Intangible } .
$$

\subsection{IMPLEMENTATION FRAMEWORK}

The architecture presented in this paper is implemented in Jason multi-agent platform [5]. Besides interpreting the original AgentSpeak(L) language, thus disposing of logic programming capabilities, Jason also features extensibility by userdefined internal actions, written in Java. Hence, it has been possible to easily 
implement aggregation methods. Further details about architecture formal background and implementation are reported in [11].

\subsection{EXAMPLES OF RESUlts}

The presented manager agent architecture has been tested over different scenarios. Simulations conducted off-line have been validated by team experts. Here is an example of explanation for the manager's decision over a landscape unit. Let the manager's individual decision be the following:

$$
\text { manager }_{\text {ind }}=\text { Intangible } \succ \text { Recuperation } .
$$

Arguments for Intangible are:

$$
\begin{gathered}
\text { Endangered_species } \& \text { Tropical_forest } \rightarrow \text { Maximal_protection } . \\
\text { Intangible } \rightarrow \text { Maximal_protection }
\end{gathered}
$$

Arguments for Recuperation are:

$$
\begin{gathered}
\text { Fire }{ }^{3} \text { Agricultural_activities } \rightarrow \text { Recover_deteriorated_zone } \\
\text { Recuperation } \rightarrow \text { Recover_deteriorated_zone. }
\end{gathered}
$$

\section{Conclusion}

In this paper, we have presented the architecture of an artificial decision maker agent for the SimParc project, a serious game about participatory management of protected areas. The possible lack of human expert resources and the desire for experiences reproductibility and control were the main motivations for the design of an artificial decision maker. It can justify its behavior and generate a participatory decision. Conflicts between arguments can be reported, thus enhancing user comprehension. We also presented a decision theory framework responsible for generating a participatory decision. The final integration of the park manager agent within the new version of the prototype is under way. We have conducted new game sessions with experts in January 2010. Besides the project specific objectives, we also plan to study the possible generality of our prototype for other types of human-based social simulations.

More information about the SimParc project is available at:

http://www-desir.lip6.fr/ ${ }^{\sim}$ briot/simparc/

Acknowledgements. We thank previous members of the project: Diana Adamatti, Ivan Bursztyn, Paul Guyot, Altair Sancho and Davis Sansolo for their past participation; CNRS-Cemagref Ingénierie Ecologique, MCT/CNPq/CT-INFO Grandes Desafios and ARCUS French Ministry of Foreign Affairs - Région Ile-de-France research programs for their current and past support. 


\section{REFERENCES}

[1] D.F. Adamatti, J.S. Sichman and H. Coelho, Virtual players: From manual to semiautonomous RPG, in Proc. of AIS-CMS'O7 International Modeling and Simulation Multiconference (IMSM'07), Buenos Aires, Argentina, edited by F. Barros, C. Frydman, N. Giambiasi and B. Ziegler. The Society for Modeling Simulation International (SCS) (2007) pp. $159-164$.

[2] L. Amgoud and S. Kaci, On the generation of bipolar goals in argumentation-based negotiation, in Argumentation in Multi-Agent Systems. LNCS, 3366, Springer (2005) 192-207.

[3] J.-P. Aubin, Viability theory, Modern Birkhäuser Classics (1992).

[4] O. Barreteau, The joint use of role-playing games and models regarding negotiation processes: Characterization of associations. J. Artif. Societies Social Simulation 6 (2003).

[5] R.H. Bordini, M. Wooldridge and J.F. Hübner, Programming Multi-Agent Systems in AgentSpeak using Jason, Wiley Series in Agent Technology, John Wiley \& Sons (2007).

[6] G. Choquet, Theory of capacities. Annales de l'Institut Fourier 5 (1953) 131-295.

[7] P.M. Dung, On the acceptability of arguments and its fundamental role in nonmonotonic reasoning, logic programming and n-person games. Artif. Intell. 77 (1995) 321-357.

[8] P. Guyot and S. Honiden, Agent-based participatory simulations: Merging multi-agent systems and role-playing games. J. Artif. Societies Social Simulation 9 (2006).

[9] P. Moraitis, Un modèle de raisonnement pour agents autonomes fondé sur l'argumentation, in Journées Nationales de Modèles de Raisonnement (JNMR'03), Paris, France (2003).

[10] I. Rahwan and L. Amgoud, An argumentation based approach for practical reasoning, in Proc. of the 5th International Joint Conference on Autonomous Agents and Multiagent Systems (AAMAS'06), Hakodate, Japan, ACM (2006) pp. 347-354.

[11] A. Sordoni, Conception et implantation d'un agent artificiel dans le cadre du projet SimParc, Master's thesis, EDITE, Université Pierre et Marie Curie (Paris 6), Paris, France (2008).

[12] E. Vasconcelos, J.-P. Briot, M. Irving, S. Barbosa and V. Furtado, A user interface to support dialogue and negotiation in participatory simulations, edited by N. David and J.S. Sichman, in Multi-Agent-Based Simulation IX, LNAI, 5269, Springer (2009) 127-140.

[13] E. Vasconcelos, G. Melo, J.-P. Briot, V.S. Patto, A. Sordoni, M. Irving, I. Alvarez and C. Lucena, A serious game for exploring and training in participatory management of national parks for biodiversity conservation: Design and experience, in Proc. of the VIIIth Brazilian Symposium on Games and Digital Entertainment (SBGAMES'09), Rio de Janeiro, Brazil (2009), pp.53-60. 